\title{
FUNCTIONAL PROPERTIES OF TINI CONICAL WORKING ELEMENTS IN THE HOLDING AND RELEASE DEVICE
}

\author{
Eugene S. Ostropiko \\ Theory of Elasticity Department, \\ Saint Petersburg State University, \\ St. Petersburg, RUSSIA \\ Es-ostropiko@mail.ru
}

\author{
Alexander I. Razov \\ Theory of Elasticity Department, \\ Saint Petersburg State University, \\ St. Petersburg, RUSSIA \\ a.razov@spbu.ru
}

Article history:

Received 01.12.2018, Accepted 19.12.2018

\begin{abstract}
Functional properties of conical working elements of the holding and release device for space application needed to control the device were investigated. The elements had $45 \mathrm{~mm}$ in diameter, $11 \mathrm{~mm}$ in height and $2 \mathrm{~mm}$ in thickness, and were made of TiNi shape memory alloy with characteristic temperatures of martensitic transformations $M_{f}=30^{\circ} C, M_{s}=45^{\circ} C, A_{s}=$ $55^{\circ} \mathrm{C}, A_{f}=75^{\circ} \mathrm{C}$. Constraint forces and displacement recovery of the conical working elements as functions of the temperature were received. It was found that the friction loss for two conical elements put one in the other one reach $15 \%$. A simple graphical method to evaluate the displacement recovery and constraint forces of such conical working elements needed to control the device is proposed.
\end{abstract}

\section{Key words}

Shape memory effect, TiNi, martensitic transformations, conical working element, holding and release device, space applications.

\section{Introduction}

Shape memory alloys (SMA) have the unique ability to recover a preliminary inelastic residual strain when heated through the reverse martensitic transformation temperatures interval. On this basis, a large number of devices have been developed [Jani et al., 2014; DesRoches and Smith, 2004; Razov and Cherniavsky, 2003; Razov, 2004; Torra et al., 2015]. These devices are used to various systems control. In turn, these devices also need to be controlled [Ashrafiuon and Elahinia, 2015; Benafan et al., 2014]. SMA elements can also be used to control of various processes
[Volkov et al., 2014; Torra et al., 2015].

One of the promising devices types are SMA holding and release devices for space applications [Razov and Cherniavsky, 2003; Hartl and Lagoudas, 2007; Rongqiang et al., 2016]. SMA holding and release devices have characteristics better than classical pyrotechnic devices [Peffer et al., 2000]. In connection with these control tasks, it is necessary to know the dependence of their functional properties on the largest possible number of initial and external parameters for each working element made of SMA [Collado et al., 2014; Hartl et al., 2015]. Among SMA working elements the wire elements operating in tension mode feature the highest working capacity and widely used in various fields [Razov, 2004; Hartl and Lagoudas, 2007; Jani et al., 2014]. However, big length of such elements, which is needed to provide the required working stroke, makes impossible a little size of a device. To reduce the size of the device we can use rod working elements operating in torsion or bending mode, or more complicated shape elements, for example conical element. With their smaller dimensions, conical elements are able to provide a rather good combination of displacement recovery and constraint forces. This paper presents the results of the experimental study of the conical working elements functional properties in the holding and release device for space applications.

\section{Experimental}

Conical elements made of TiNi alloy with characteristic temperatures of martensitic transformations $M_{f}=$ $30^{\circ} \mathrm{C}, M_{s}=45^{\circ} \mathrm{C}, A_{s}=55^{\circ} \mathrm{C}, A_{f}=75^{\circ} \mathrm{C}$ were tested. The rings with an external diameter of $50 \mathrm{~mm}$ and an internal diameter of $15 \mathrm{~mm}$ were made of sheets with a thickness of $2 \mathrm{~mm}$. In a special device conical elements were formed of these rings. The initial dimensions of received conical elements were $d=$ $19.5 \mathrm{~mm}, D=45,5 \mathrm{~mm}, h=11.05 \mathrm{~mm}, \delta=2 \mathrm{~mm}$ 


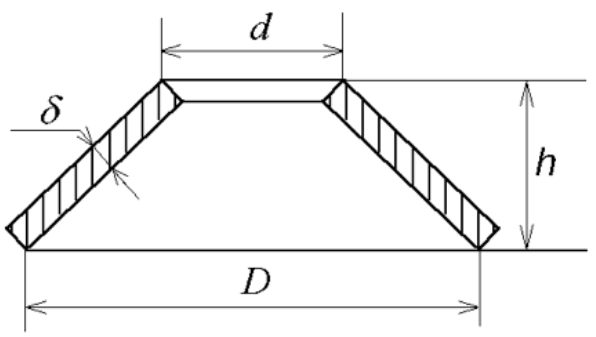

Figure 1. Conical working element
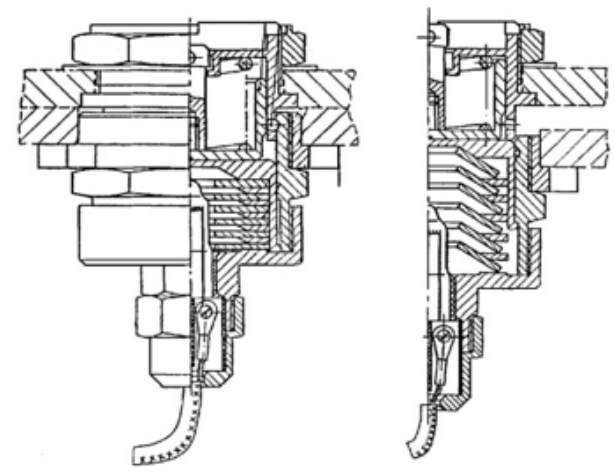

Figure 2. Holding and release device

(see Fig. 1). These dimensions were due to the space in which the holding and release device had to be placed. After compressing at room temperature, the element dimensions changed as follows: $d=16,4 \mathrm{~mm}, D=$ $50,35 \mathrm{~mm}, h=5,4 \mathrm{~mm}$. The functional properties of conical elements were investigated in a real locking and release device (Fig. 2). Heating of the elements was carried out using a halogen filament lamp with a power of $150 \mathrm{~W}$ and voltages up to $27 \mathrm{~V}$, which heated the elements by infrared radiation. A Shimadzu AG-XD plus test machine was used to measure the constraint forces.

\section{Results and Discussion}

During the uniform heating then the element fully recovered its initial shape. Fig. 3 shows the dependence of the conical element height on the temperature during the heating and cooling in a free state at the heating rate of $5^{\circ} \mathrm{C} / \mathrm{min}$. Constraint force characteristics of the conical elements were investigated, when the elements were in the holding and release device, by heating them by a halogen filament lamp. The lamp was put inside the element, but had no contact with it. The force was measured with the $37 \mathrm{kN} / \mathrm{mm}$ rigidity. Before every test the holding and release device with working elements was compressed by about $200 N$ force to reduce backlash in the device. A thermocouple inside the conical element, touching it surface in the middle, was used to measure temperature in all the tests. Fig 4 shows how the constraint force output of the conical elements

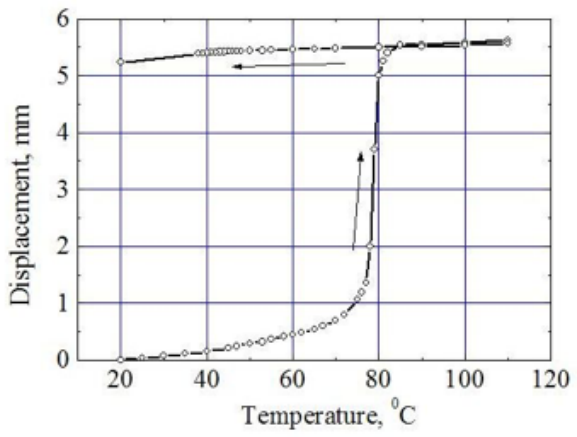

Figure 3. Displacement of conical element at uniform heatingcooling after compression

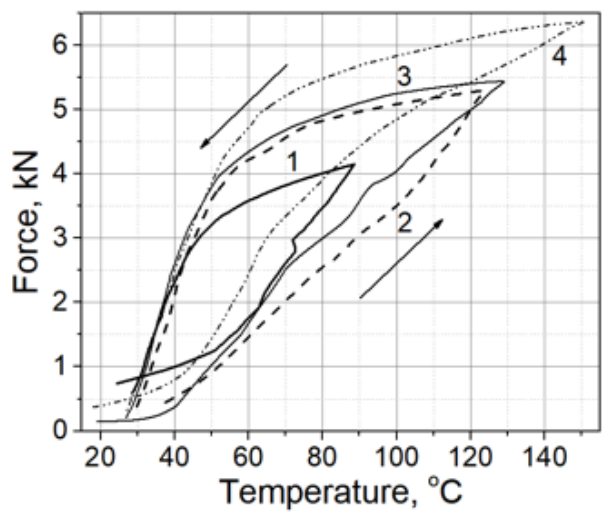

Figure 4. Constraint force output of conical element at heating under voltage of $20 \mathrm{~V}(1) ; 25 \mathrm{~V}(2) ; 27 \mathrm{~V}(3,4)$, and force relaxations at cooling

depends on the temperature in four consequent heatingcooling tests, with heater voltage of $20 \mathrm{~V}$ (1), $25 \mathrm{~V}$ (2) and $27 \mathrm{~V}(3,4)$. During cooling, there was an accumulation of reversible strain due to the direct martensitic transformation plasticity. The thermocouple, put as described above, measured, actually, the temperature of the air in the working chamber of the device. Besides, because the heater was inside the working element, the temperature was changing non-uniformly by volume of the element, causing the start of martensitic transformation near the inner diameter $\mathrm{d}$, and, then its gradual propagation to the outer diameter $\mathrm{D}$. Therefore, the heating-stage curves in Fig. 3 have no change in slopes typical for martensitic transformation. At the stage of cooling, when the lamp is off, thermal conditions are almost the same for both the whole working chamber and conical elements, which is confirmed by the coincidence of the relevant parts of the curves (1)-(4). By combining SMA conical elements, we can achieve desired displacement recovery and constraint forces. If increased stroke is required, the elements should be arranged one towards another. In this case, no loss in the constraint force will happen, and working strokes will add together. Another situation can be observed 


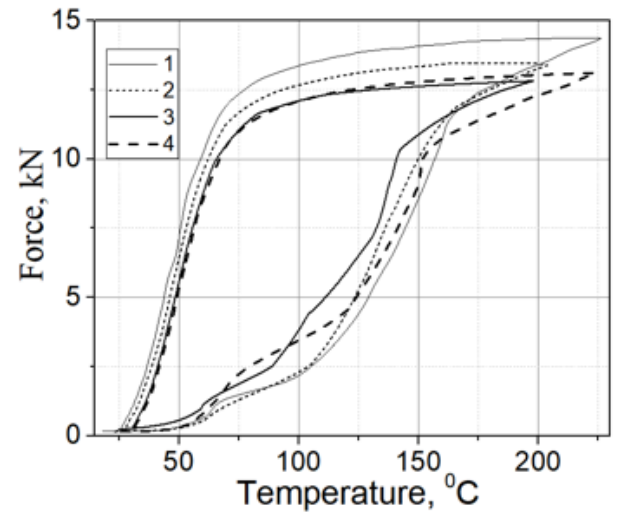

Figure 5. Generation and relaxation of constraint forces arising in two conical elements, put one in the other one, during four subsequent cycles of heating and cooling (1-4)

if we need to increase the constraint force keeping the stroke at the same level. To achieve this, conical elements should be arranged by putting one in another, despite possible friction losses during the shape recovery at heating. The following experiment was carried out to estimate such losses. Two conical elements, both precompressed, put one in the other, were undergone four heating-cooling cycles in the device. In Fig. 5 below, we can see constraint forces arising in the conical elements (the numbers of curves 1-4 correspond those of the thermo cycles).

We can suppose that the constraint forces become steady in the first four thermo cycles. Actually, the maximum values of the constraint forces in the third and the fourth cycles differ insignificantly. Then, the conical elements were taken out from the device and each of them was thermocycled once again. As can be seen in Fig. 6, after the heating-cooling cycles the behavior of the elements changed, namely, the energy accumulated by them in the cooling was shared unequally. The accumulation of reversible strain was due to the direct martensitic transformation plasticity The inner element accumulated more energy than the outer one did. If we compare the curve (3) in Fig. 6 with the curve (4) in Fig. 5, we can see that the difference between them is about $15 \%$ which can be attributed to the friction losses. Based on the above experimental data for the evaluation of the SMA conical elements work output, we can offer the scheme shown in Fig. 7. It is known that the dependence of displacement recovery of a working element on constraint force is close to quadratic curve. Therefore, if we know what is the displacement recovery of one or two working elements in free state as well as what is the maximum of constraint force developed by them at absolutely rigid fixing, we can describe the intermediate values of the displacement recovery as linear functions of the constraint forces as in Fig. 7. We can guarantee that the devices equipped with conical elements with the intermediate

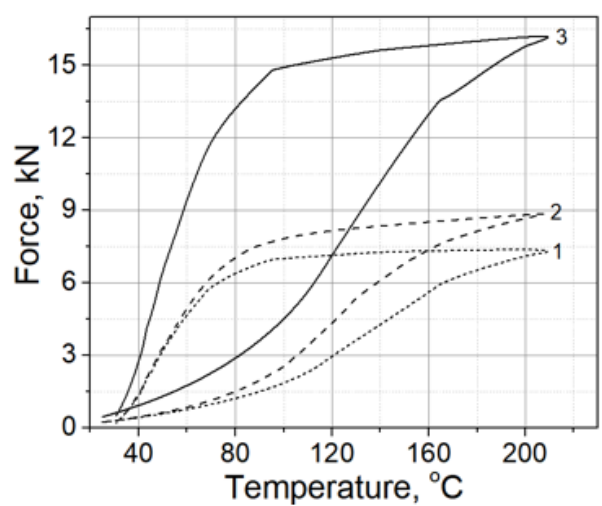

Figure 6. Generation and relaxation of the constraint forces in outer (1) and inner (2) conical elements, and the sum (3) of (1) and (2) after the cycles shown in Fig. 5

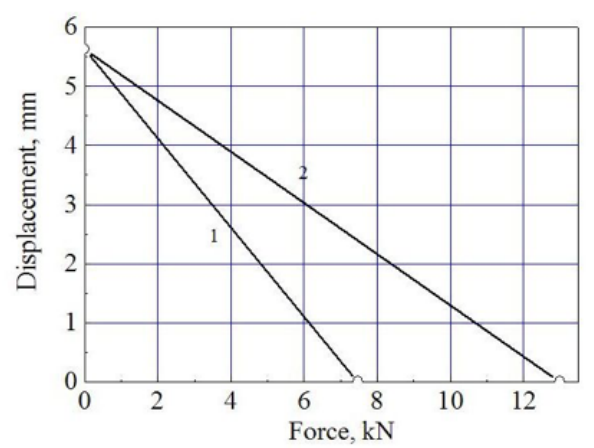

Figure 7. Linear approximation of the displacement recovery of one (1) or two (2) SMA conical elements, depending on constraint force

values of displacement recovery and constraint force, chosen in such a way, will be able to work, because the quadratic curve will be above our linear curve. Thus, we can use the linear approximation when designing devices and their SMA working elements. The obtained dependences can serve as a basis for creating control systems for different devices with conical working elements of such sizes. This method can be extended to other sizes of conical elements.

\section{Conclusions}

In this paper the study of the shape memory alloy conical elements functional properties, which can be used to create various control systems, was carried out. Shape memory alloy conical elements enable to design compact devices providing a good combination of displacement recovery and constraint forces. By increasing the number of conical elements, we can easily increase the working stroke or produced forces of the device, or both. If there is a need to increase the constraint forces, the friction losses between the elements should be taken into account. A simple graphical method to evaluate the displacement recovery and 
constraint forces of such conical working elements needed to control the device is proposed. In addition, the data obtained can serve as a basis for the design of control devices of power grids, safety systems of power-generating facilities, heat-sensitive actuators using SMA conical working elements.

\section{References}

Ashrafiuon, H. and Elahinia, M.H. (2015). Control of SMA Actuators. In Shape Memory Alloy Actuators: Design, Fabrication and Experimental Evaluation. John Wiley \& Sons:125-154.

Benafan, O., Brown, J., Calkins, F.T., Kumar, P., Stebner, A.P., Turner, T.L., Vaidyanathan, R., Webster, J., and Young, M.L. (2014). Shape memory alloy actuator design: CASMART collaborative best practices and case studies. Int. J. Mechanics and Materials in Design. 10(1):1-42.

Collado, M., Cabás, R., San Juan, J., and LópezFerreño, I. (2014). Functional characterization of a novel shape memory alloy. Journal of materials engineering and performance, 23(7):2321-2326.

DesRoches, R. and Smith, B. (2004). Shape memory alloys in seismic resistant design and retrofit: a critical review of their potential and limitations. Journal of Earthquake Engineering, 8(3):415-429.

Hartl, D., Mabe, J., Benafan, O., Coda, A., Conduit, B., Padan, R., and Van Doren, B. (2015). Standardization of shape memory alloy test methods toward certification of aerospace applications. Smart Materials and Structures, 24(8):082001.

Hartl, D. J. and Lagoudas, D. C. (2007). Aerospace applications of shape memory alloys. Proceedings of the Institution of Mechanical Engineers, Part G:
Journal of Aerospace Engineering, 221(4):535-552.

Jani, J. M., Leary, M., Subic, A., and Gibson, M. A. (2014). A review of shape memory alloy research, applications and opportunities. Materials \& Design (1980-2015), 56:1078-1113.

Peffer, A. C., Fosness, E. R., Carpenter, B. F., and Denoyer, K. K. (2000). On-orbit experiments and applications of shape memory alloy mechanisms. In Smart Structures and Materials 2000: Industrial and Commercial Applications of Smart Structures Technologies, 3991, pp. 187-195. International Society for Optics and Photonics.

Razov, A. (2004). Application of titanium nickelidebased alloys in engineering. Physics of Metals and Metallography, 97(S1):S97-S126.

Razov, A. and Cherniavsky, A. (2003). Application of SMAs in modern spacecraft and devices. In Journal de Physique IV (Proceedings), 112, pp. 1173-1176. EDP sciences.

Rongqiang, L., Yan, W., Qiang, C., and Dong, L. (2016). Design and experiment on a lock/release mechanism based on shape memory alloy for SAR Antenna. In Advances in reconfigurable mechanisms and robots II, pp. 991-1007. Springer.

Torra, V., Isalgue, A., Lovey, F. C., and Sade, M. (2015). Shape memory alloys as an effective tool to damp oscillations. Journal of Thermal Analysis and Calorimetry, 119(3): 1475-1533.

Volkov, A. E., Evard, M. E., Redkina, K. V., Vikulenkov, A. V., Makarov, V. P., Moisheev, A. A., Markachev, N. A., and Uspenskiy, E. S. (2014). Simulation of payload vibration protection by shape memory alloy parts. Journal of materials engineering and performance, 23(7): 2719-2726. 